\title{
Comparison of mAbs Targeting Epithelial Cell Adhesion Molecule for the Detection of Prostate Cancer Lymph Node Metastases with Multimodal Contrast Agents: Quantitative Small-Animal PET/CT and NIRF
}

\author{
Mary A. Hall*1, Kenneth L. Pinkston*1,2, Nathaniel Wilganowski ${ }^{1}$, Holly Robinson ${ }^{1}$, Pradip Ghosh ${ }^{1}$, Ali Azhdarinia ${ }^{1}$, \\ Karina Vazquez-Arreguin ${ }^{1,2}$, Arseniy M. Kolonin ${ }^{1}$, Barrett R. Harvey ${ }^{1,2}$, and Eva M. Sevick-Muraca ${ }^{1}$ \\ ${ }^{1}$ Center for Molecular Imaging, Brown Foundation Institute of Molecular Medicine, University of Texas Health Science Center, \\ Houston, Texas; and ${ }^{2}$ Division of Applied Biologics, Brown Foundation Institute of Molecular Medicine, University of Texas Health \\ Science Center, Houston, Texas
}

\begin{abstract}
The proliferation of most carcinomas is associated with an overexpression of epithelial cell adhesion molecule (EpCAM), a 40-kDa type I transmembrane protein found on epithelial cells yet absent from other cell types. The absence of EpCAM in normal lymphatics makes it an attractive marker for studying lymph node (LN) metastases of carcinomas to improve LN staging accuracy. Herein, we developed and quantitatively compared dual-labeled monoclonal antibodies (mAbs) of varying affinities against EpCAM for both noninvasive and intraoperative detection of metastatic LNs in prostate cancer. Methods: A panel of hybridoma-derived anti-EpCAM mAbs was generated and screened. Two high-affinity candidate mAbs with specificity for nonoverlapping epitopes on the EpCAM extracellular domain were chosen for further evaluation. After conjugation with DOTA for ${ }^{64} \mathrm{Cu}$ radiolabeling and IRDye $800 \mathrm{CW}$ as a fluorophore, dual-labeled specific or isotype control mAb was administered intravenously to male nu/nu mice at 10-12 wk after orthotopic implantation of DsRedexpressing PC3 cells. Within 18-24 h, noninvasive small-animal $\mathrm{PET} / \mathrm{CT}$ and in vivo, in situ, and ex vivo DsRed reporter gene and near-infrared fluorescence (NIRF) imaging were performed to detect primary tumors and metastatic LNs. Using DsRed fluorescence as the true indicator of cancer-positive tissue, we performed receiver operating characteristic curve analyses of percentage injected dose per gram measured from quantitative small-animal PET/CT and fluorescence intensity measured from semiquantitative NIRF imaging for each LN examined to compare mAb sensitivity and specificity. Results: mAbs 7 and 153 generated in-house were found to have higher affinity than commercial mAb 9601. Accuracy, as a function of
\end{abstract}

\footnotetext{
Received Mar. 21, 2012; revision accepted Apr. 30, 2012.

For correspondence contact either of the following: For imaging, Eva M. Sevick-Muraca, Center for Molecular Imaging, Brown Foundation Institute of Molecular Medicine, University of Texas Health Science Center, SRB 330, 1825 Pressler St., Houston, TX 77030.

E-mail: eva.sevick@uth.tmc.edu

For mAbs, Barrett R. Harvey, Center for Molecular Imaging, Brown Foundation Institute of Molecular Medicine, University of Texas Health Science Center, SRB 330, 1825 Pressler St., Houston, TX 77030.

E-mail: barrett.harvey@uth.tmc.edu

${ }^{*}$ Contributed equally to this work.

Published online Aug. 7, 2012.

COPYRIGHT (C 2012 by the Society of Nuclear Medicine and Molecular Imaging, Inc.
}

sensitivity and specificity, for the detection of cancer-positive LNs during in vivo small-animal PET/CT was highest for mAbs 7 (87.0\%) and $153(78.0 \%)$ and significantly greater $(P<0.001)$ than random chance (50.0\%). Rates for mAb 9601 (60.7\%) and control mAb 69 (27.0\%) were not significantly different from chance. Similarly, mAb 7 had significant detection accuracy by NIRF imaging $(96.0 \%, P<0.001)$. Conclusion: mAbs 7 and 153 are attractive, high-affinity candidates for further multimodal imaging agent optimization aimed at enhancing sensitivity and specificity for detection of metastatic LNs in prostate cancer. Fully quantitative NIRF imaging is needed for comprehensive analyses of NIRF-labeled agent accuracy for intraoperative guidance.

Key Words: dual-labeled mAb; EpCAM; small-animal PET/CT; NIRF imaging; lymph node (LN) metastases

J Nucl Med 2012; 53:1427-1437

DOI: 10.2967/jnumed.112.106302

D ual-labeled contrast agents promise the advantage of noninvasive imaging via nuclear techniques and molecularly guided surgical resection via near-infrared fluorescence (NIRF) imaging (1). Currently, nodal staging of most cancers is performed after lymph node (LN) biopsy and dissection for subsequent pathologic examination. As in most cancers, imaging of LN involvement in prostate cancer (PCa) lacks sensitivity and specificity (2) and as a result, extended pelvic $\mathrm{LN}$ dissection, which provides higher staging accuracy (3), is rapidly becoming the standard of care at the time of radical prostatectomy. Yet, with the early detection of PCa enabled by prostate-specific antigen screening, a substantial and growing population of PCa patients may be overtreated (4) and encounter resultant morbidity such as lymphocele, thrombotic events, urethral nerve and vascular injury, and lymphedema (5-7). A multimodal contrast agent is needed to provide accurate, non- 
invasive LN staging of $\mathrm{PCa}$ and to guide surgical resection of cancer-positive LNs while sparing resection of cancernegative LNs and potentially reducing surgical morbidity and improving survivorship.

Epithelial cell adhesion molecule (EpCAM) is overexpressed in many metastasizing epithelial cancers (8-12) and may be an ideal target for dual-labeled agent development. Expression of EpCAM in prostatic biopsy samples has been shown through immunohistochemistry to be elevated with biochemical recurrence (13) and correlated with Gleason score $(13,14)$, which is an important prognostic factor and is now incorporated into PCa staging nomograms (15). In more than 441 human PCa tissue samples, microarray analyses showed that $80 \%-100 \%$ of all prostatic intraepithelial neoplasia, localized $\mathrm{PCa}$, hormone-refractory local recurrences, and LN metastases overexpressed EpCAM, suggesting it as an excellent diagnostic imaging marker for PCa LN staging (16).

Previously, we developed a dual-labeled anti-EpCAM monoclonal antibody (mAb) for multimodal diagnostic imaging in a preclinical model of metastatic PCa, but optimization of binding affinity and pharmacodynamics of antibody-based agents is needed to maximize imaging sensitivity and specificity (17). Although anti-EpCAM mAbs have been under investigation as therapeutics against epithelial cancers, development has been focused on attenuating binding affinity to reduce systemic toxicity and enhancing antibody-dependent cellular cytotoxicity and complementdependent cytotoxicity for therapeutic action (18). As a diagnostic, the design of anti-EpCAM mAb-based imaging agents requires enhanced affinity for improved specificity at subtherapeutic dosages, elimination of pharmacologic action through antibody-dependent cellular cytotoxicity and complement-dependent cytotoxicity, and reduced circulation times to improve target-to-background ratios (TBRs).

Herein, we developed a panel of mAbs specific for human EpCAM, from which high-affinity candidates with specificity for nonoverlapping EpCAM epitopes were dual-labeled with a near-infrared (NIR) fluorophore and a conventional chelator and radiotracer, for subsequent assessment via NIRF imaging and quantitative smallanimal PET/CT in a DsRed reporter gene mouse model of PCa LN metastasis. We sought to first assess whether differences in binding affinity affected quantitative imaging performance of whole mAb-based contrast agents assessed by receiver operating characteristic (ROC) curve analyses before engineering mAb fragment-based imaging agents that would lack properties of therapeutic antibodydependent cellular cytotoxicity and complement-dependent cytotoxicity but would have improved imaging pharmacokinetics. A commercially available anti-EpCAM mAb, which was dual-labeled and used in a subset of animals in previous preclinical imaging (17), was evaluated in the ROC curve analyses for the comparison and selection of candidate mAbs for further optimization of imaging agents.

\section{MATERIALS AND METHODS}

\section{mAb Panel Generation}

Commercially available mouse $\operatorname{IgG}_{2 b} \mathrm{mAb}$ 9601, specific for human EpCAM, was purchased from R\&D Systems and maintained at $-20^{\circ} \mathrm{C}$ before labeling. To generate in-house anti-EpCAM mAbs, $\mathrm{BALB} / \mathrm{c}$ mice were immunized with either recombinant human (rhu) EpCAM/Fc (960-EP; R\&D Systems) or MCF7 cells (HTB-22; American Type Culture Collection [ATCC]), a human breast adenocarcinoma line that expresses EpCAM $(18,19)$. EpCAM/Fc was administered using standard methods as previously described (20). For whole-cell immunization, MCF7 cells were grown in Dulbecco's modified Eagle's medium (DMEM) (Invitrogen Corp.) with $10 \%$ fetal bovine serum to $80 \%-100 \%$ confluency in T75 flasks, detached with trypsin-ethylenediaminetetraacetic acid (Cellgro), washed in phosphate-buffered saline (PBS) (pH 7.4), and injected intraperitoneally at $10^{7}$ cells per mouse every $10 \mathrm{~d}$ for 5 injections. Mouse splenocytes were collected and fused with SP2/0 mouse myeloma cells (20). mAbs from parental wells were evaluated for binding specificity to rhuEpCAM/Fc via an enzyme-linked immunosorbent assay, followed by kinetic screening to rank-order high-affinity clones using surface plasmon resonance (SPR) (21).

\section{Competitive Binding Assays}

To compare relative binding sites, we used a competitive binding strategy to separate our mAb panel into groups having competing or noncompeting epitope binding sites. Briefly, a horseradish peroxidase (HRP) labeling kit (Zymed Laboratories) was used to label mAbs generated in-house or commercial mAb 9601. RhuEpCAM/ Fc was coated on Microlon 600 (Greiner Bio-One) 96-well highbinding plates in PBS at $0.5 \mu \mathrm{g} / \mathrm{mL}$ at $4^{\circ} \mathrm{C}$ overnight. After being blocked with PBS containing $0.02 \%$ polysorbate-20 and $5 \%$ nonfat dry milk for $1 \mathrm{~h}$ and subsequent washing with PBS and $0.02 \%$ polysorbate, each selected mAb from our panel was added to the plate at $2 \mu \mathrm{g} / \mathrm{mL}$ and incubated for $30 \mathrm{~min}$ at room temperature. This procedure was followed by the addition of HRP-conjugated $\mathrm{mAb}$ at $0.2 \mu \mathrm{g} / \mathrm{mL}$ and incubation for $30 \mathrm{~min}$ at room temperature. The ability of HRP-conjugated mAb to bind rhuEpCAM/Fc was detected via reaction with $3,3^{\prime}, 5,5^{\prime}$-tetramethylbenzidine substrate (Sigma-Aldrich) and by measurement of the optical density (OD, absorbance at $450 \mathrm{~nm}$ ), using the manufacturer's protocol. Binding of HRP-labeled mAb demonstrated that epitopes were available for binding, whereas the absence of binding by HRP-labeled $\mathrm{mAb}$ indicated competitive epitope binding by the primary $\mathrm{mAb}$.

\section{Preparation of Fragment Antigen-Binding (Fab) Regions}

Purified mouse $\mathrm{IgG}_{1}$ - in-house mAbs 7 and 153 — was digested with immobilized Ficin (kit 44980; Pierce), according to the manufacturer's protocol. Commercial mAb 9601, $\mathrm{IgG}_{2 \mathrm{~b}}$, was digested with immobilized Papain (kit 44985; Pierce). Briefly, purified IgG was dialyzed overnight and buffer exchanged with provided digestion buffers without cysteine-HCl. After a digestion period of 3-4 h, samples were applied to the provided protein A column. The pass-through material containing Fab regions was dialyzed against PBS and retained for enrichment via size-exclusion chromatography. An ÄKTA Explorer (GE Healthcare) fast protein liquid chromatography system coupled with a Superdex $200 \mathrm{HR}$ $10 / 30$ fast protein liquid chromatography column (GE Healthcare) preequilibrated with PBS was used to separate the Fab regions from undigested $\operatorname{IgG}$ and $\mathrm{F}\left(\mathrm{ab}^{\prime}\right)_{2}$. Purity was then assessed by sodium dodecyl sulfate-polyacrylamide gel electrophoresis. 
SPR Assessment of Equilibrium Affinity Constant, $K_{D}$

To discriminate between monovalent and multivalent interactions on quantitative SPR measurements of $K_{D}$, the binding affinities of the Fab regions of mAbs were measured using SPR and a Biacore T100 instrument (GE Healthcare). Two flow cells of a CM5 chip were coated with goat antihuman IgG (Fc-specific) (Jackson ImmunoResearch) to approximately 8,000 resonance units with an NHS/EDC Amine Coupling Kit (BR-1000-50; GE Healthcare). All measurements were made at $25^{\circ} \mathrm{C}$ using $\mathrm{HBS}$ $\mathrm{EP}+(10 \mathrm{mM}$ HEPES, $150 \mathrm{mM} \mathrm{NaCl}, 3 \mathrm{mM}$ ethylenediaminetetraacetic acid, $0.05 \% \mathrm{v} / \mathrm{v}$ polysorbate $20, \mathrm{pH} 7.4$ ) as running buffer. EpCAM/Fc ligand (R\&D Systems) was diluted in HBS$\mathrm{EP}+$ to $0.5 \mu \mathrm{g} / \mathrm{mL}$ and applied to the coated chip surface. Fab regions were then tested at 5 different molar concentrations starting at $50 \mathrm{nM}$ after a 2 -fold dilution series was performed. Flow cells were regenerated with $100 \mathrm{mM}$ phosphoric acid. All samples were applied in duplicate.

\section{Confirmation of mAb Whole-Cell Binding Activity}

PC3 cells (human prostate adenocarcinoma line, CRL-1435; ATCC), grown to 80\%-100\% confluency in DMEM with $10 \%$ fetal bovine serum, were treated with trypsin-ethylenediaminetetraacetic acid and resuspended in PBS containing $2 \%$ bovine serum albumin (BSA). One million cells per well were labeled with mAb (5 $\mu \mathrm{g} / \mathrm{mL}$ ) in a $200-\mu \mathrm{L}$ volume and incubated on ice for $20 \mathrm{~min}$. After being washed with PBS-BSA, phycoerythrin-conjugated donkey $\mathrm{F}\left(\mathrm{ab}^{\prime}\right)_{2}$ antimouse $\mathrm{IgG}$ (Jackson ImmunoResearch) at $5 \mu \mathrm{g}$ per sample was added for an additional $20 \mathrm{~min}$ of incubation. Cells were washed again with PBS-BSA and fixed in $2 \%$ paraformaldehyde before being analyzed (10,000 events) on a FACSCalibur Flow Cytometer (BD Biosciences). Analyses of mean fluorescence intensities (MFI) were performed using WinMDI2.9 software (J. Trotter, Scripps Institute).

\section{Production of mAbs for Animal Model}

One-liter cultures of hybridomas producing selected mAbs were grown in DMEM high-glucose medium supplemented with $2 \%$ fetal bovine serum for $10 \mathrm{~d}$. Supernatants were centrifuged, filtered $(0.2 \mu \mathrm{m})$, and purified on a Protein G column (GE Healthcare) per the manufacturer's instructions. Samples were dialyzed against PBS, filtered $(0.2 \mu \mathrm{m})$, and stored at $4^{\circ} \mathrm{C}$ until use.

\section{Testing Species Cross-Reactivity of mAbs}

To determine whether mAbs specific for human EpCAM crossreact with murine EpCAM, the human cell line MCF7 and 4T1 cells (mouse mammary carcinoma, CRL-2539; ATCC) were used. Hybridoma cells were grown and mAbs purified. Rat antimouse EpCAM mAb G8.8 (Developmental Studies Hybridoma Bank, University of Iowa) was used as a positive control for detection of EpCAM on 4T1 cells. After incubation $\left(20 \mathrm{~min}, 4^{\circ} \mathrm{C}\right)$ with $\mathrm{mAb}$, cells were washed with PBS-BSA and either DyLIGHT-488-conjugated donkey antirat IgG (Jackson ImmunoResearch) or phycoerythrinconjugated donkey $\mathrm{F}\left(\mathrm{ab}^{\prime}\right)_{2}$ antimouse IgG (Jackson ImmunoResearch) was added $(5 \mu \mathrm{g} / \mathrm{sample} \times 20 \mathrm{~min})$ for detecting cells bound by rat antimouse or mouse antihuman EpCAM mAb, respectively. Cells were washed again, fixed in $2 \%$ paraformaldehyde, and analyzed (10,000 events) on a FACSCalibur Flow Cytometer using WinMDI2.9 software.

\section{Preparation of Dual-Labeled mAbs}

mAbs were dual-labeled with DOTA chelator and IRDye $800 \mathrm{CW}$ and purified, and the number of chelates and dye molecules conjugated per mAb was determined according to procedures described previously $(17,22)$. mAb conjugates were labeled by adding $37 \mathrm{MBq}(1 \mathrm{mCi})$ of ${ }^{64} \mathrm{CuCl}_{2}$ (Radiologic Sciences, Washington University Medical School) to $100 \mu \mathrm{g}$ of $\mathrm{mAb}$ conjugate in $0.1 \mathrm{M} \mathrm{NaOAc}$ at $\mathrm{pH} 6.0$, followed by incubation at $40^{\circ} \mathrm{C}$ for $1 \mathrm{~h}$. Reactions were purified as described above and analyzed by radio-thin-layer chromatography and radio-high-performance liquid chromatography.

\section{Determination of Contrast Agent Biologic Activity}

NIR flow cytometry was used to measure the biologic activity of $\mathrm{mAb}$ conjugates before use in animals according to a previously validated method (23). Briefly, human PCa cells (PC3 cell line; ATCC), which overexpress EpCAM (24), were incubated with fluorophore-labeled anti-EpCAM or control mAb in $\mathrm{PBS}, \mathrm{pH}$ 7.4. Commercial $\operatorname{IgG}_{2 \mathrm{~b}}$ (BD Pharmingen) and in-house $\mathrm{IgG}_{1}$ isotype control mAbs were used in each assay to test for nonspecific binding. As a positive control, IRDye-labeled goat antimouse IgG (LI-COR) was added to reactions containing cells incubated with unlabeled, commercial mAb 9601. As a negative control, secondary antibody was also added to cells without primary antibody. A customized FACSAria II with NIR detection capability (BD Biosciences) was used for analysis. The percentage of cells bound, or stained, by fluorophore-labeled antibody and the MFI of the cells in each reaction were recorded. The means and SDs were calculated from 3 experiments for each $\mathrm{mAb}$ tested.

\section{Animal Model}

A DsRed reporter gene mouse model of PCa LN metastasis was used as previously described (17). In brief, 6- to 8-wk-old, male $\mathrm{nu} / \mathrm{nu}$ mice (Charles River) were housed and maintained in compliance with protocols approved by the Animal Welfare Committee at the University of Texas Health Science Center at Houston and the Association for Assessment and Accreditation of Laboratory Animal Care. PC3 cells, which were transfected with p-DsRedExpress-N1 (Clontech Laboratories, Inc.) and sorted as previously described (17), were orthotopically implanted $\left(1 \times 10^{6}\right.$ cells $)$ in the dorsal prostate of each mouse. Noninvasive, longitudinal DsRed fluorescence imaging was performed biweekly to monitor tumor growth.

Dual-labeled mAbs (40-50 $\mu \mathrm{g}, 7.4-12.95 \mathrm{MBq})$ were administered via the tail vein at 10-12 wk after implantation. Within 18-24 h, noninvasive small-animal PET/CT was performed and immediately followed by in vivo, in situ, and ex vivo DsRed reporter gene and NIRF optical imaging.

\section{PET, NIRF, and DsRed Fluorescence Imaging}

Noninvasive small-animal PET/CT was performed using an Inveon System (Siemens Medical Solutions) with multimodality CT and docked PET. Images were analyzed using Inveon Research Workplace software (Siemens Medical Solutions) by drawing regions of interest (ROIs) around signal-bearing tissues and nonsignal-bearing background tissues and by computing the percentage injected dose per gram $(\% \mathrm{ID} / \mathrm{g})$ for each ROI. TBRs were computed from the \%ID/g normalized to muscle background. Previously, we showed that LN DsRed fluorescence measured in situ or ex vivo provided comparable or better true-positive LN discrimination than pathology (17). Consequently, we used in situ or ex vivo DsRed fluorescence as a measure of ground truth for LN cancer positivity and computed the PET true-positive rate (or sensitivity) versus false-positive rate (or [1 - specificity]) of all LNs examined using ascending TBRs as positive cutoff criteria 
during ROC curve analyses. The area under the curve (AUC), or accuracy rate, was then computed, and sensitivity and specificity rates at the optimal TBR cutoff value that maximized the function of the respective ROC curve were found for each dual-labeled $\mathrm{mAb}$ tested.

Fluorescence imaging was conducted using custom-built instrumentation described elsewhere (17). For DsRed fluorescence imaging, excitation light was supplied at $568 \mathrm{~nm}$ by a tunable, aircooled, argon-krypton laser, and emission light $(610 \pm 5 \mathrm{~nm})$ was collected through a bandpass filter (Andover Corp.). During NIRF imaging, a laser diode excited at $768 \mathrm{~nm}$, and emission light $(830 \pm 5 \mathrm{~nm})$ was collected through 2 tandem bandpass filters (25). Although quantitative NIRF imaging has not been validated in the way that small-animal PET has, we performed semiquantitative analyses using ImageJ software (National Institutes of Health). ROIs were drawn on NIRF signal-positive and signalnegative LNs and background tissue found in 2-dimensional in situ images, and MFI was recorded for each ROI. TBRs were computed from the MFI for each LN analyzed by normalizing to background tissue. Using DsRed fluorescence as the ground-truth indicator for cancer-positive LNs as described above, we performed ROC curve analyses of TBRs of MFI for LNs imaged in situ, and the AUC, sensitivity, and specificity at the optimal TBR were found for each $\mathrm{mAb}$ used during NIRF imaging.

\section{Data Analyses}

General statistical comparisons of mAbs were made using the Student $t$ test, unpaired, or a 1-way ANOVA as appropriate with Office Excel 2007 (Microsoft Corp.) or SigmaPlot 11 (Systat Software, Inc.) software. For determining the accuracy, sensitivity, and specificity of each $\mathrm{mAb}$ using different imaging modalities via ROC curve analyses, SigmaPlot 11 software was used. A 95\% confidence interval $(P<0.05)$ was considered significant.

\section{RESULTS}

\section{Anti-EpCAM mAbs Selected by Off-Rate Analysis and Competitive Binding}

Screening and analyses of single-cell clones from parental wells of hybridoma fusions were performed as previously described $(20,21)$ and yielded a mAb panel with slower offrates than that of commercial mAb 9601 (Fig. 1). During competitive binding assays, binding of some mAbs, including mAbs 17, 73, 81, 144, and 153, to EpCAM blocked binding by $\mathrm{mAb} 9601$, suggesting shared binding epitopes (Fig. 2A). However, mAbs 7, 18, 33, 38, 66, 70, 83, 85, 124, 133, and 138 did not inhibit mAb 9601 binding, suggesting epitopes that do not overlap or binding sites that do not compete with that of mAb 9601 (Fig. 2B). From subsequent analysis that compared mAb 7 with the mAb panel, we found that $\mathrm{mAbs}$ that do not have overlapping epitope binding with mAb 9601 have an overlapping footprint with $\mathrm{mAb}$ 7. Thus, the mAb panel could be categorized into 2 unique groups with specificity for 2 separate, nonoverlapping epitopes on the EpCAM protein. mAbs from each group, mAbs 153 and 7, were chosen for further evaluation.

\section{SPR Assessment of Anti-EpCAM mAbs 7 and 153 Fab Regions}

Fab regions of mAb 153 demonstrated a slower $k_{d}(F a b$ dissociation constant) or off-rate than did those of $\mathrm{mAb} 7$, which in turn were slower than those of mAb 9601 Fab regions, a trend consistent with SPR analysis of dissociation avidity of captured $\operatorname{IgG}$ antibody using the bivalent EpCAM/Fc as the analyte (Table 1). In addition, mAb 7 Fab regions demonstrated a faster on-rate $\left(k_{a}\right.$, Fab association constant) than did $\mathrm{mAb} 9601$ and mAb $153 \mathrm{Fab}$ regions. $\mathrm{K}_{\mathrm{D}}$ was $15.4,0.54$, and $2.3 \mathrm{nM}$ for $\mathrm{mAb} 9601$, 153 , and 7 Fab regions, respectively. These $K_{D}$ values translated to a 28- and 7-fold increase in affinity of mAbs 153 and 7 above mAb 9601, respectively.

\section{mAb Whole-Cell Binding Activity}

As seen with mAb 9601, both mAb 7 and mAb 153 effectively bound PC3 cells as demonstrated by specific binding during flow cytometry (Fig. 3). From triplicate reactions, an MFI increase of 3.9-, 4.8-, and 2.9-fold was found for cells bound by mAbs 7, 153, and 9601, respectively, relative to the MFI of cells stained with phycoerythrin-conjugated secondary antibody alone. This result provides evidence that in addition to recognizing recombinantly expressed EpCAM/Fc, these mAbs generated inhouse recognize native EpCAM on the cell surface.

\section{Species Cross-Reactivity of mAbs Tested by Whole-Cell Binding}

The generated panel of antihuman EpCAM mAbs bound only the human cells and did not bind to mouse 4T1 cells at detectable levels (Supplemental Figs. 1A and 1C show results from $\mathrm{mAb} 153$ that are representative of those from the entire mAb panel; supplemental materials are available online only at http://jnm.snmjournals.org). Conversely, rat antimouse EpCAM mAb G8.8 demonstrated binding to the 4T1 cells but not to human MCF7 cells (Supplemental Figs. $1 \mathrm{~B}$ and 1D).

\section{Contrast Agent Characterization}

DOTA conjugation to mAbs occurred at varying levels for each reaction, ranging from 3.0 to 4.6 DOTA molecules per $\mathrm{mAb}$, whereas conjugation of IRDye $800 \mathrm{CW}$ to the mAbs resulted in IRDye800/protein (D/P) ratios ranging from 2.1 to 3.4 (Table 1 ). Although radiolabeling reactions were performed identically, radiochemical yields were affected by amounts of chelate conjugated and were $60 \%-$ $80 \%$. Radiochemical purities were greater than $90 \%$ for mAb 9601 and greater than $95 \%$ for all other conjugates, with typical specific activities of $0.185-0.259 \mathrm{MBq}$ (5-7 $\mu \mathrm{Ci}$ ) per microgram of protein.

Using fluorescence microscopy, we previously demonstrated that DOTA-mAb 9601-IRDye bound to the surface of PC3 cells but not lymphatic epithelial cells, which lack EpCAM surface expression (17), and we reported more recently the validation of a cell-binding assay using NIR flow cytometry when PC3 cells were grown to $80 \%-100 \%$ confluency (23). Because we have observed via flow cytometric analysis decreased binding of mAb 9601 to PC3 cells grown to less than $70 \%$ confluency (data not shown), PC3 cells were consistently grown to $80 \%-100 \%$ confluency for all work in the present study to limit variability in EpCAM 


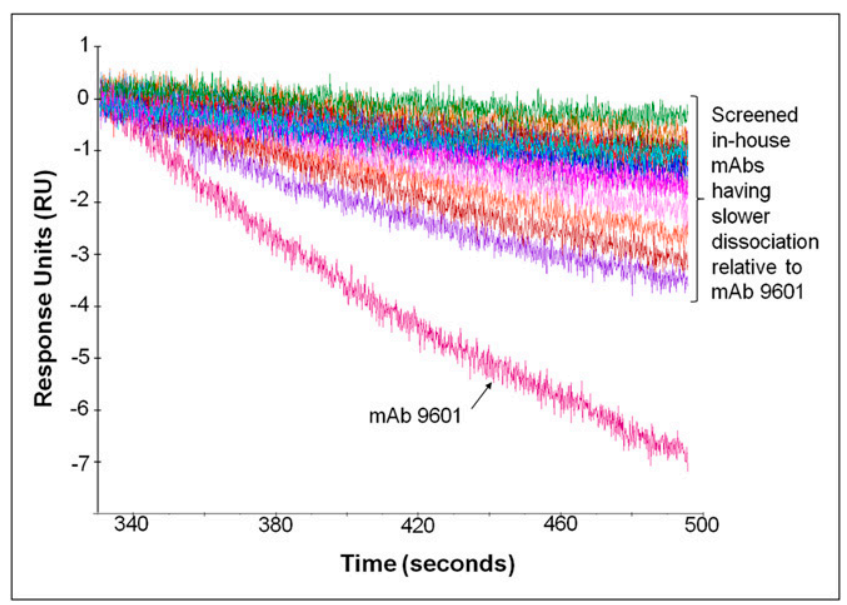

FIGURE 1. Dissociation analysis of mAbs from EpCAM/Fc by SPR analysis. In series, in-house panel of mAbs and commercial mAb 9601 were captured on CM5 sensor chip coupled with goat antimouse IgG, followed by EpCAM/Fc analyte. Dissociation of $\mathrm{EpCAM} / \mathrm{Fc}$ from $\mathrm{mAb}$ is monitored as decrease in response units over time.

surface expression levels and for comparison of mAb conjugate biologic activity.

From NIR flow cytometry, we found that PC3 cells stained by IRDye-labeled mAbs 7 and 153 had significantly higher MFIs $(1,722.0 \pm 57.4$ and 1,359.3 \pm 94.8 MFI units, respectively) than $\mathrm{PC} 3$ cells bound by conjugated $\mathrm{mAb}$ 9601 (1,087.0 \pm 74.0 MFI units), whereas the MFI for $\mathrm{mAb} 7$ was also significantly higher than that for $\mathrm{mAb}$ 153 ( $P<0.05$, Fig. 4). $\mathrm{IgG}_{1}$ isotype control mAb 69 had a significantly lower MFI (124.7 \pm 7.3 MFI units) than $\mathrm{mAbs} 7$ and $153(P<0.05)$, and commercial $\mathrm{IgG}_{2 \mathrm{~b}}$ isotype control mAb (149 \pm 6.0 MFI units) (data not shown) had a lower MFI than mAb 9601. The biologic activity, measured as the mean percentage of PC 3 cells stained, of conjugated $\mathrm{mAb} 7(86.4 \% \pm 1.8 \%)$ was significantly greater than that of IRDye-labeled mAb $9601(79.5 \% \pm 0.8 \%)$ $(P<0.05$, Table 1$)$. Although the biologic activity of $\mathrm{mAb}$ $153(81.8 \% \pm 1.5 \%)$ was also higher than that of $\mathrm{mAb} 9601$, the difference was not found to be significant. The percentage of cells stained by $\operatorname{IgG}_{1}$ isotype control mAb $69(3.2+0.3 \%)$ was significantly low relative to mAbs 7 and 153 , as was the percentage of cells stained by commercial $\mathrm{IgG}_{2 \mathrm{~b}}$ isotype control $\mathrm{mAb}(0.7 \% \pm 0.1 \%)$ relative to mAb $9601(P<0.05)$. The MFI (1,116.5 \pm 54.5 MFI units) and the percentage $(80.2 \% \pm 5.5 \%)$ of cells bound by unlabeled mAb 9601 , followed by incubation with IRDye-labeled secondary antibody, were not significantly different from that of cells stained directly by conjugated mAb 9601, demonstrating that the NIR fluorophore label did not significantly hinder $\mathrm{mAb}$ binding to its target on $\mathrm{PC} 3$ cells.

\section{Multimodal Imaging}

Noninvasive, DsRed fluorescence imaging of each mouse at 2-wk intervals allowed for monitoring of primary prostate tumors and detection of LN involvement in some animals. Although some metastatic LNs could be easily visualized, it was necessary to hold the abdominal skin taut on some mice for LN staging (Supplemental Fig. 2). By weeks 10-12 after implantation, metastases usually involved the lumbar LNs and sometimes also medial iliac, renal, sciatic, inguinal, or popliteal LNs.

From noninvasive small-animal PET/CT, a radiotracer signal from primary prostatic tumors and LNs bound by dual-labeled $\mathrm{mAb}$ was detected. Figure 5 shows coronal, sagittal, and 3-dimensional views from small-animal PET/ CT of a representative mouse, administered dual-labeled $\mathrm{mAb} 153$, in which the prostate, lumbar, and renal LNs and 1 sciatic LN were PET-positive. In situ DsRed reporter gene imaging (Figs. 5D and 5G) demonstrated the presence of PC3 cells in the same tissues, confirming a primary tumor and LN metastases. DsRed fluorescence in this animal's right sciatic LN was observed during in vivo imaging of the dorsal side and ex vivo imaging. Similarly, in situ NIRF imaging of the same mouse (Figs. 5E and 5H) demonstrated that the same cancer-positive tissue could be detected from specifically bound, dual-labeled mAb 153 . The tissues are also shown in white-light images (Figs. 5F and 5I). Radiotracer and NIRF signals were also detected in the liver, kidneys, and bladder, which is not uncommon for a whole-mAb imaging agent. Although dual-labeled mAb 153 was administered to the mouse shown in Figure 5, these images are representative of multimodal imaging of cancer-positive LNs by all 3 anti-EpCAM mAbs tested in the current study, because similar images were also captured of mice given mAbs 7 and 9601. To compare mAb performance in our metastatic PCa model, quantitative analyses of both in vivo small-animal PET/CT and in situ NIRF imaging were conducted.

\section{Quantitative Small-Animal PET Image Analyses}

Table 2 lists the mean TBR of \%ID/g for DsRed-positive LNs in PCa-positive mice and the AUC for each duallabeled $\mathrm{mAb}$ tested. Although the percentage of DsRed-positive (i.e., cancer-positive) LNs found in each group of mice was similar (range, 10\%-14\%), the mean TBRs for DsRedpositive LNs in mice administered dual-labeled mAbs 7 (5.79 $\pm 3.3 \% \mathrm{ID} / \mathrm{g})$ and $153(3.77 \pm 0.9 \% \mathrm{ID} / \mathrm{g})$ were significantly higher $(P<0.05)$ than the mean TBR for DsRed-positive LNs in mice given the dual-labeled isotype control mAb 69 $(1.79 \pm 0.9 \% \mathrm{ID} / \mathrm{g})$. No significant difference was found between TBRs for in-house mAbs 7 and 153; however, the mean TBR found for mAb $9601(3.68 \pm 3.2 \% \mathrm{ID} / \mathrm{g})$ was significantly lower than that for mAb $7(P<0.05)$.

Figure 6 shows the ROC curve generated from quantitative small-animal PET for each dual-labeled $\mathrm{mAb}$ tested. The AUC for mAbs 7 (87.0\%) and 153 (78.0\%) were both significantly greater than the $50 \%$ nondiscriminatory line $(P<0.001)$, whereas the AUC for mAb 9601 (60.7\%) was not significantly different from a 50/50 random guess (Table 2). The AUC (27\%) for isotype control mAb 69, which is specific for pili expression in Enterococcus faecalis (26), 
FIGURE 2. Competitive binding analysis identified 2 independent epitopes recognized by mAb panel. Unlabeled mAb clones ( $x$-axis) bound EpCAM-coated enzymelinked immunosorbent assay plates, followed by addition of either HRP-labeled anti-EpCAM mAb 9601 or mAb 7. Competing and noncompeting epitopes were visualized after they were washed and HRP substrate added. Competing epitopes of $m A b 9601$ (A) and mAb 7 (B) were those identified that inhibited binding of HRPlabeled $\mathrm{mAb}$, whereas noncompeting epitopes did not inhibit binding of labeled $m A$ bs as monitored by HRP signaling ( $y$-axis). OD = optical density (absorbance at $450 \mathrm{~nm}$ ).

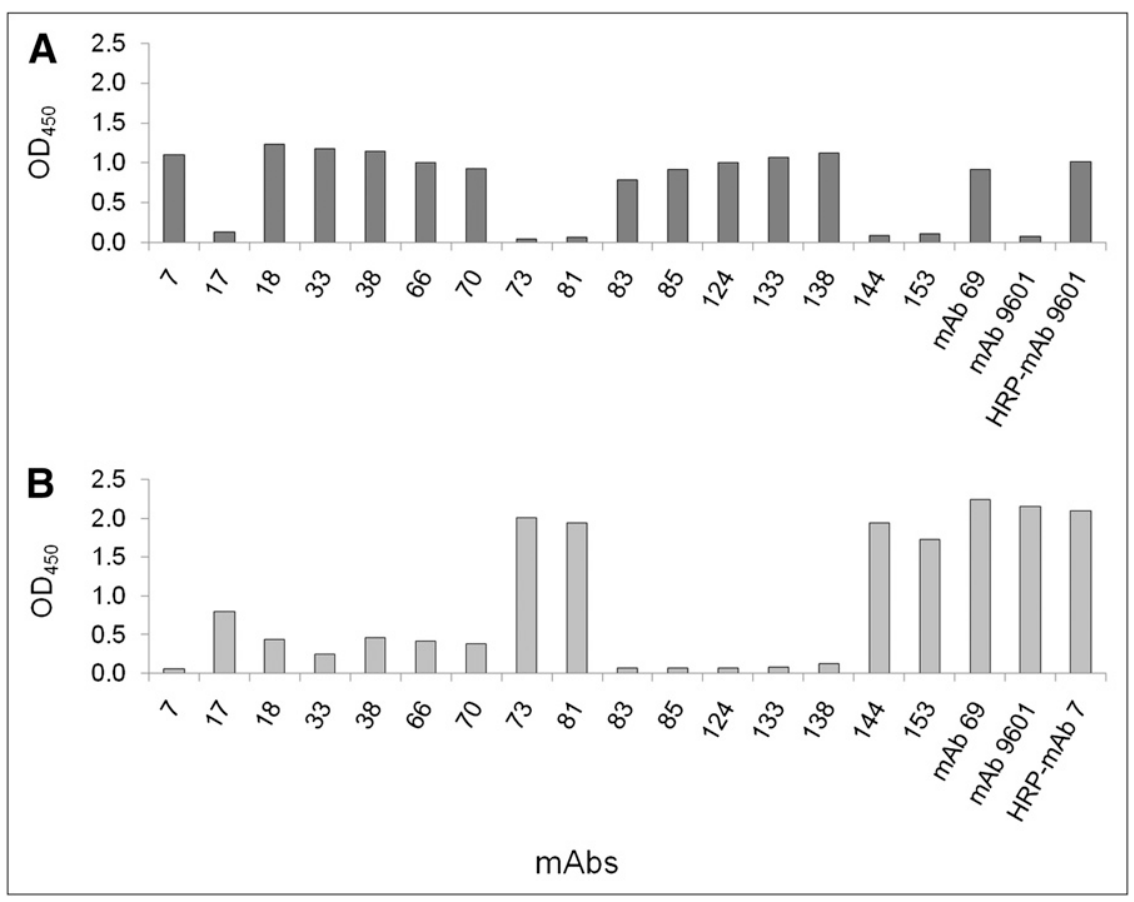

was less than $50 \%$. Given that a perfect classification in ROC analysis is defined as a true-positive rate of 1.0 and a false-positive rate of 0 , mAbs 7 and 153 each demonstrated better classification or concordance between smallanimal PET/CT and DsRed reporter gene signals and overall higher sensitivity than commercial mAb 9601 and control mAb 69. Using the optimal TBR cutoff value that maximized the function of the ROC curve generated for each mAb (Table 2), we found that corresponding sensitivities for in-house mAbs 153 (94.4\%) and 7 (92.9\%) were substantially greater than the sensitivity found for commercial mAb 9601 (66.7\%). Specificities were similar for all 3 anti-EpCAM conjugates.

\section{NIRF Image Analyses}

Although NIRF imaging has not been validated for quantitative imaging in the way that small-animal PET has, we nonetheless computed the MFI for each LN imaged in situ found from 2-dimensional NIRF images to semiquantitatively evaluate the accuracy of each dual-labeled $\mathrm{mAb}$ during NIRF imaging for potential application for intraoperative guidance during $\mathrm{LN}$ resection. As shown in Table 3, the number of LNs examined in situ during NIRF imaging was fewer than that imaged in vivo during smallanimal PET/CT (Table 2). From this subset of LNs imaged in situ, many were cancer-positive (range, 26\%-48\%). Similar to TBRs found from small-animal PET/CT, the mean TBR of MFI for mAbs 7 (5.24 \pm 0.8 MFI units) and 153 $(3.45 \pm 1.8$ MFI units) were significantly higher $(P<0.05)$ than the mean TBR for DsRed-positive LNs in mice that received dual-labeled isotype control mAb $69(1.58 \pm 0.1$ MFI units) and dual-labeled mAb 9601 (1.48 \pm 0.4 MFI units). Also, the TBR for $\mathrm{mAb} 7$ was found to be significantly higher than that for mAb $153(P<0.05)$.

TABLE 1

Characterization of Imaging Conjugates

\begin{tabular}{|c|c|c|c|c|c|c|}
\hline $\mathrm{mAb}$ & $\mathrm{k}_{\mathrm{a}}\left(\mathrm{M}^{-1} \mathrm{~s}^{-1}\right)$ & $\mathrm{k}_{\mathrm{d}}\left(\mathrm{s}^{-1}\right)$ & $\begin{array}{l}\text { Fab equilibrium } \\
\text { affinity constant } \\
\left(\mathrm{K}_{\mathrm{D}}=\mathrm{k}_{\mathrm{d}} / \mathrm{k}_{\mathrm{a}}\right)(\mathrm{nM})\end{array}$ & $\begin{array}{c}\text { No. of } \\
\text { DOTA/protein }\end{array}$ & $\begin{array}{c}\text { No. of } \\
\text { IRDye800/protein }\end{array}$ & $\begin{array}{c}\text { Percentage } \\
\text { biologic activity }\end{array}$ \\
\hline 9601 & $2.6 \times 10^{5}$ & $4.0 \times 10^{-3}$ & 15.4 & $3.0(1.0)$ & $2.3(0.5)$ & $79.5(0.8)$ \\
\hline 153 & $2.2 \times 10^{5}$ & $1.2 \times 10^{-4}$ & 0.54 & $4.6(1.1)$ & $2.1(0.5)$ & $81.8(1.5)$ \\
\hline 7 & $4.3 \times 10^{5}$ & $9.9 \times 10^{-4}$ & 2.3 & 5.1 & 2.3 & $86.4(1.8)^{\star}$ \\
\hline 69 & Not applicable $^{\dagger}$ & Not applicable & Not applicable & $4.2(2.6)$ & $3.4(0.4)$ & $3.2(0.3)^{\ddagger}$ \\
\hline $\begin{array}{l}{ }^{\star} P<0 \\
{ }^{\dagger} \text { Not a } \\
{ }^{\ddagger} P<0 \\
\text { Table } \\
\text { Data i }\end{array}$ & $\begin{array}{l}\text { for } m A b 7 \text { vs. } 9 \\
\text { cable because } n \\
\text { for } \operatorname{lgG}_{1} \text { isotype } \\
\text { mAb } 9601 . \\
\text { rentheses are } S\end{array}$ & $\begin{array}{l}\text { and } 153 . \\
99 \text { is isotype co } \\
\text { ol mAb } 69 \text { vs. m }\end{array}$ & $\begin{array}{l}7 \text { targeting pili. } \\
7 \text { and } 153 \text { and for }\end{array}$ & nercial lgG $2 \mathrm{~b}$ is & e control $(0.7 \% \pm$ & $\%$, data not showr \\
\hline
\end{tabular}

1432 The Journal of Nuclear Medicine • Vol. 53 • No. 9 • September 2012 


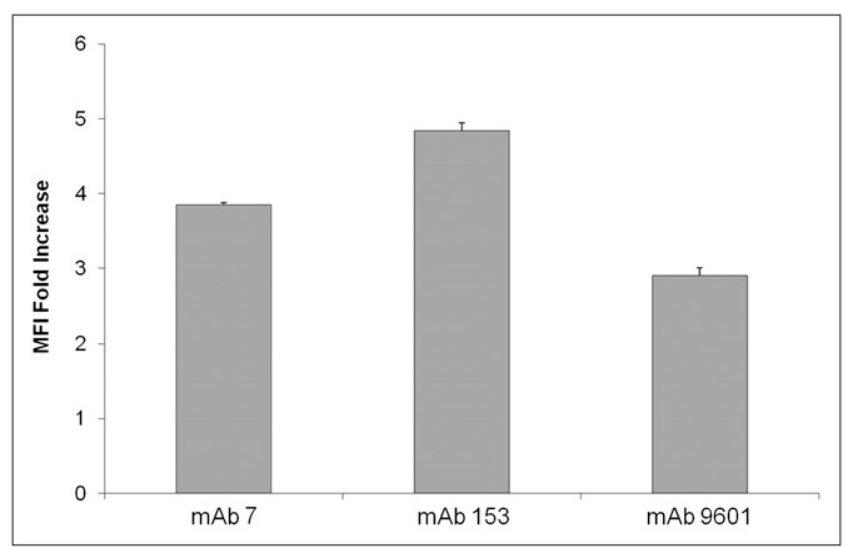

FIGURE 3. Selected candidate mAb binding to native EpCAM expression on PC3 cells, compared with that of commercial mAb 9601, via flow cytometry. Anti-EpCAM mAb 7, 153, or 9601 was incubated with PC3 cells, followed by detection with phycoerythrin-labeled secondary antibody. Geometric MFI of cell population was determined by analysis of 10,000 cells using BD FACSCalibur Flow Cytometer. Fold increase in MFI for cells incubated with each mAb is shown relative to MFI of cells incubated with only phycoerythrin-labeled secondary antibody.

ROC curve analyses (Table 3 ) of the dual-labeled mAbs from in situ NIRF imaging revealed that $\mathrm{mAb} 7$ had a significant level of accuracy $(96 \%, P<0.001)$ for detecting cancer-positive nodes with $100 \%$ sensitivity and $88.9 \%$ specificity at the curve's optimal TBR cutoff value. Although commercial mAb 9601 also demonstrated significant accuracy $(87.0 \%, P<0.006)$ using in situ NIRF imaging, with a sensitivity and specificity of $88.9 \%$ and $63.6 \%$, respectively, the accuracy rate found for in-house $\mathrm{mAb} 153$ was not significant $(58.0 \%)$ because of relatively low sensitivity $(81.3 \%)$ and markedly lower specificity (35.3\%). Again, similar to results found for small-animal
PET/CT, the AUC for isotype control mAb 69 during NIRF imaging was less than $50.0 \%$.

Given that only a subset of LNs was analyzed for in situ NIRF imaging, further ROC curve analyses were performed using data from small-animal PET/CT for the same subset of LNs to directly compare results from multimodal imaging for the exact same LNs. Similar to the trend in accuracy levels found for the different mAbs when smallanimal PET/CT data from all LNs examined were analyzed (Table 2), accuracy rates of mAbs 7, 153, 9601, and 69 for detecting metastatic nodes were $92.7 \%(P<0.001), 84.2 \%$ $(P<0.001), 58.6 \%$, and $36.0 \%$, respectively, when smallanimal PET/CT data from only the subset of LNs were analyzed (data not shown).

\section{DISCUSSION}

Sentinel LN dissection has been the standard of care in breast cancer staging and recently has been under investigation for staging $\mathrm{PCa}(27,28)$. It is also notable that with the advent of improved systemic treatment, recent studies have shown that breast cancer patients with limited sentinel LN metastases have gained no benefit from extensive LN dissection (29). Earlier detection of PCa using prostate-specific antigen testing and pelvic LN dissection may continue to decrease mortality rates due to $\mathrm{PCa}$ but may also inherently increase the risk for overtreatment in low-risk PCa patients (30), especially with the advent of new pharmacologic therapies against PCa. A molecularly targeted imaging agent that offers the benefits of both noninvasive imaging and intraoperative guidance for resection of cancer-positive LNs is needed for more accurate and effective PCa staging.

EpCAM, which is overexpressed in more than $87 \%$ of PCa cases (10), was identified $30 \mathrm{y}$ ago as a tumor-associated

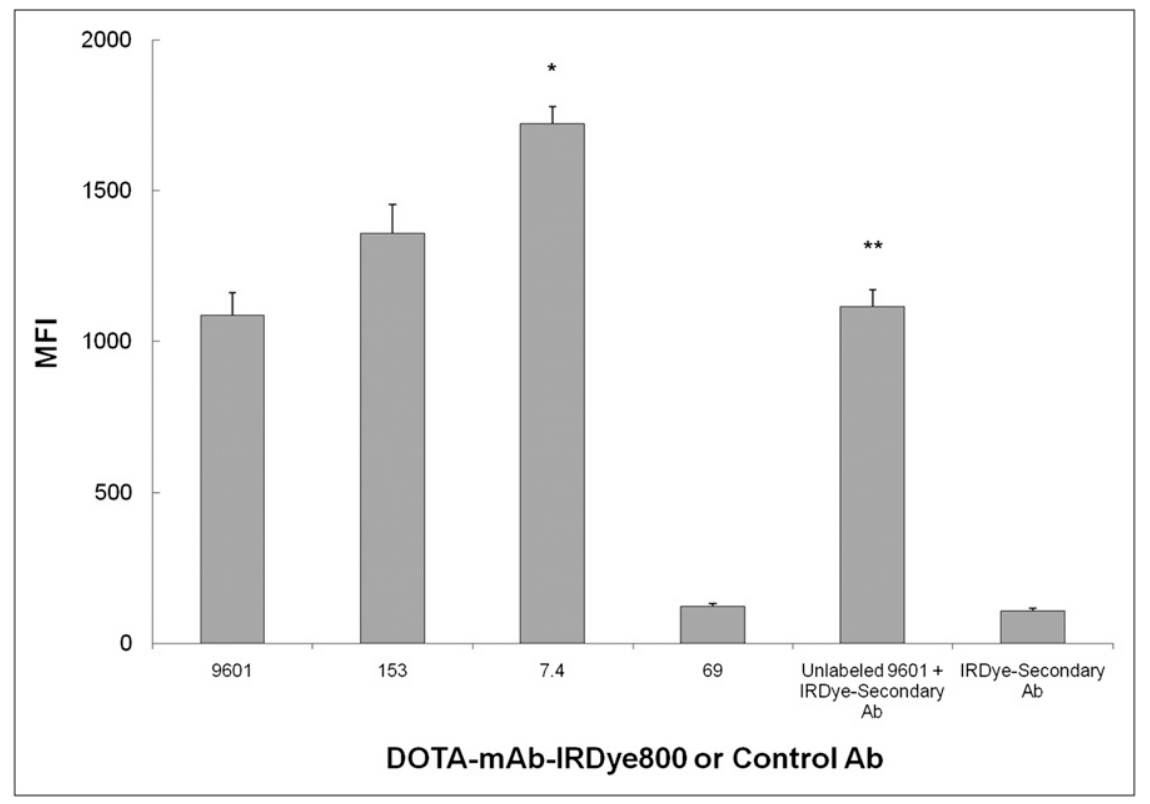

FIGURE 4. MFI of PC3 cells bound by IRDye-labeled antibody, as determined by NIR flow cytometry. After incubation with conjugated mAb 9601, 153, 7, or 69 or assay control antibody, PC3 cells were analyzed using customized BD FACSAriall. ${ }^{*} P$ $<0.05$ for mAbs 7 and 153 vs. mAb 9601 and for mAb 7 vs. mAb 153. ${ }^{* \star} P<0.05$ for unlabeled mAb 9601, followed by IRDye-labeled secondary antibody vs. IRDye-labeled secondary antibody alone. No significant difference $(P>0.05)$ was found for unlabeled mAb 9601 followed by IRDye-labeled secondary antibody vs. conjugated mAb 9601. 
FIGURE 5. Noninvasive small-animal PET/ CT and invasive DsRed and NIR fluorescence images of representative mouse having primary prostate tumor and metastatic LNs. After dual-labeled mAb 153 administration, coronal (A) and sagittal (B) views from small-animal PET/CT show radiotracer signal in prostate region and several LNs. ROls (circles) were drawn around cancer-positive tissue, and \%ID/g was calculated for each $\mathrm{ROI}$ (including background muscle tissue), both using Inveon Research Workplace software. Three-dimensional view from smallanimal PET/CT (C) demonstrates better tissue delineation relative to single-slice 2-dimensional views, including delineating primary tumor from bladder, metastatic renal LNs from kidneys and liver (where agent is cleared), and metastatic sciatic LN. In situ DsRed fluorescence images ( $D$ and $G$ ) of ventral view from same animal confirm presence of primary prostate tumor and cancerpositive lumbar LNs and renal LNs via PC3 cell DsRed reporter gene expression. Same cancer-positive tissues were detected via in situ NIR fluorescence imaging $(E$ and $H)$ due to specific binding by dual-labeled $\mathrm{mAb}$ (agent). Anatomic location of tissue is depicted by corresponding white-light photographs ( $F$ and $\mathrm{I}$ ) taken during in situ imaging. LLNs = lumbar LNs; RLNs = renal LNs; SLN = sciatic $\mathrm{LN}$.
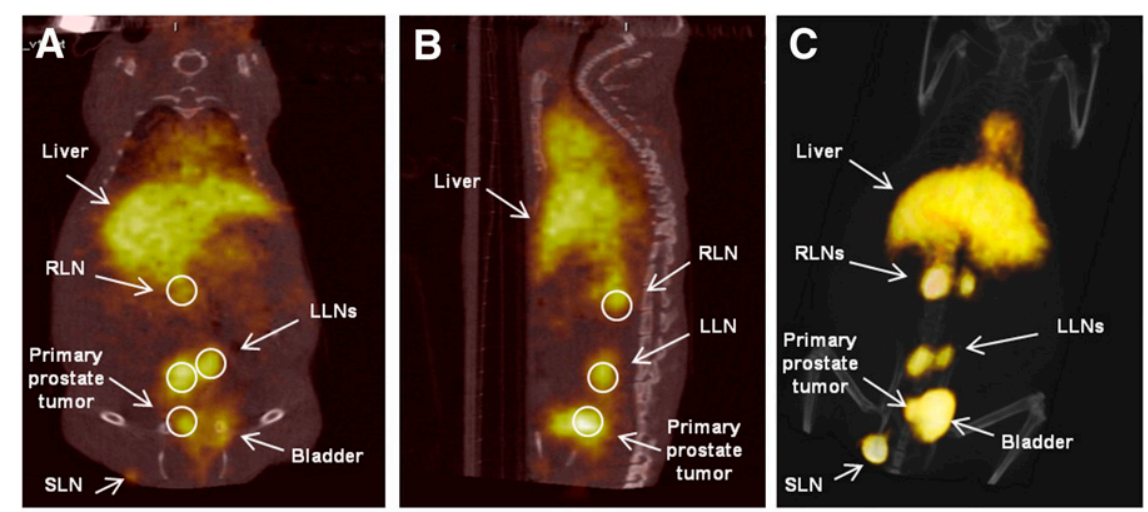

DsRed (gene reporter)
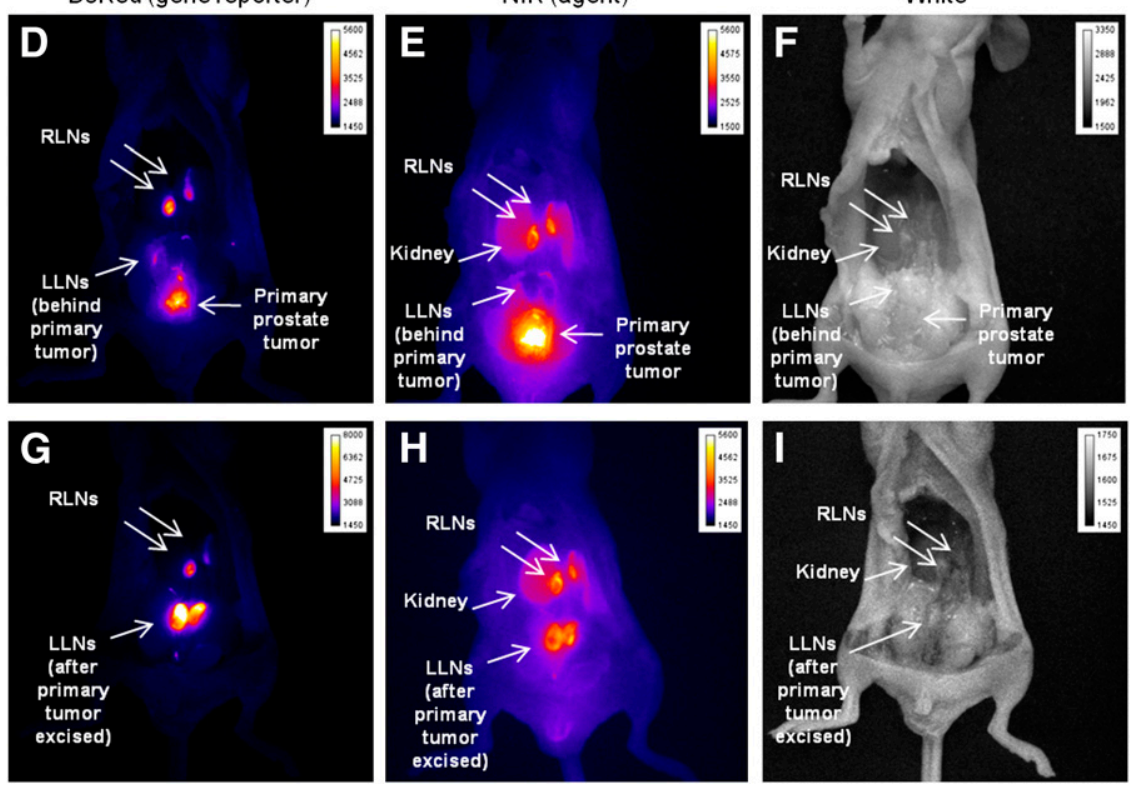

antigen that today is known to be intensely expressed on many epithelial carcinomas while being less intensely expressed and less accessible on the basolateral surface of normal epithelia (12,31-33). When administered therapeutically, anti-EpCAM $\mathrm{mAbs}$ with the highest binding affinities are not well tolerated in clinical studies. Instead, anti-EpCAM mAbs with attenuated affinities exhibit less systemic toxicity and have been moderately successful in clinical trials (18). Yet, when administered as a diagnostic at subtherapeutic dosages, the attenuated affinity of anti-EpCAM mAbs could potentially affect imaging sensitivity, thus motivating our studies to evaluate imaging performance. Furthermore, when used in imaging diagnostics, mAbs are often converted to antibody fragments, which maintain antigen binding activity but have reduced circulation times, thus producing more desirable pharmacokinetics to reduce background imaging signal (34). However, affinity-attenuated $\mathrm{mAb}$ fragments often result in reduced targeting and imaging sensitivity, lacking the relatively long half-life needed to find their target. Although others have used therapeutic mAbs as radiolabeled and fluorescently labeled diagnostic agents in clinical and preclinical studies, we sought to first develop mAbs with the highest affinities and assess imaging performance before further modification.
Our SPR-based selection strategy allowed the identification of high-affinity mAbs produced from hybridoma clones for testing in our mouse model of human PCa LN metastases. Imaging analysis was accelerated using a fluorescent DsRed reporter gene as ground truth during assessment of LN metastases. Consistent with SPR affinity of their Fab region measurements, dual-labeled mAbs 153 and 7 as noninvasive small-animal PET/CT agents possessed greater sensitivity than commercial mAb 9601 and had a significantly higher accuracy rate than random chance. In contrast, the AUC of mAb 9601 was not significantly greater than the $50 \%$ line of nondiscrimination. Although the TBRs of $\% \mathrm{ID} / \mathrm{g}$ of cancer-positive LNs imaged in vivo using dual-labeled mAbs 153 and 7 were significantly greater than that found using $\mathrm{mAb} 69$, and the TBR of $\%$ ID/g using mAb 7 was significantly greater than that found using mAb 9601, there was no significant difference between the TBRs of $\% \mathrm{ID} / \mathrm{g}$ for dual-labeled mAbs 153 and 7, even though their measured Fab region affinities differed by 4 -fold.

From NIRF imaging, TBRs of MFI for both mAb 153 and $\mathrm{mAb} 7$ were significantly high, compared with both commercial mAb 9601 and control mAb 69, whereas the 
TABLE 2

Quantitative Small-Animal PET Image Analyses Using DsRed-Positive LNs as True-Positive Indicator of LN Metastases

\begin{tabular}{|c|c|c|c|c|c|c|c|c|c|}
\hline \multirow[b]{3}{*}{$\mathrm{mAb}$} & \multirow{3}{*}{$\begin{array}{l}\text { No. of mice } \\
\text { tested }\end{array}$} & \multicolumn{2}{|r|}{ LNs examined } & \multirow{2}{*}{\multicolumn{2}{|c|}{$\begin{array}{l}\text { TBR of } \\
\% \text { ID } / g^{*}\end{array}$}} & \multirow{3}{*}{$\begin{array}{c}\mathrm{AUC}^{\dagger} \\
(\%)\end{array}$} & \multirow{3}{*}{$\begin{array}{c}\text { Sensitivity } \\
\text { (\%) }\end{array}$} & \multirow{3}{*}{$\begin{array}{l}\text { Specificity } \\
(\%)\end{array}$} & \multirow{3}{*}{$\begin{array}{c}\text { Optimal TBR } \\
\text { cutoff }(\% / D / g)\end{array}$} \\
\hline & & \multirow[b]{2}{*}{$n$} & \multirow{2}{*}{$\begin{array}{l}\text { Percentage DsRed- } \\
\text { positive }\end{array}$} & & & & & & \\
\hline & & & & Mean & SD & & & & \\
\hline 9601 & 10 & 136 & 11 & 3.68 & 3.2 & 60.7 & 66.7 & 70.3 & 2.81 \\
\hline 153 & 9 & 125 & 14 & $3.77^{\ddagger}$ & 0.9 & $78.0^{\S}$ & 94.4 & 65.4 & 2.67 \\
\hline 7 & 10 & 109 & 13 & $5.79^{\ddagger}$ & 3.3 & $87.0^{\S}$ & 92.9 & 67.4 & 2.44 \\
\hline 69 & 15 & 167 & 10 & 1.79 & 0.9 & 27.0 & 43.8 & 38.4 & $\begin{array}{c}\text { Not } \\
\text { applicable"l }\end{array}$ \\
\hline $\begin{array}{l}{ }^{*} \text { Mean } \\
{ }^{\dagger} \mathrm{AUC} \\
{ }^{\ddagger} P<0 \\
{ }^{\S} P<0 \\
{ }^{\S} \text { Not ar }\end{array}$ & $\begin{array}{l}\text { ( } \pm \mathrm{SD}) \text { of } \% \mathrm{I} \\
\text { ROC curve a } \\
\text { or mAbs } 7 \text { an } \\
\text { for mAbs } 7 \\
\text { able because }\end{array}$ & $\begin{array}{l}\text { for D } \\
\text { sis (c } \\
3 \text { vs. } \\
153 \text { v } \\
b 69\end{array}$ & $\begin{array}{l}\text { d-positive LNs in pros } \\
\text { s are shown in Fig. 6) } \\
69 \text { and for mAb } 7 \text { vs. } \\
\text { UC of } 50 \% \text { (line of no } \\
\text { otype control. }\end{array}$ & $\begin{array}{l}\text { cancer- } \\
9601.1 \\
\text { criminat }\end{array}$ & $\begin{array}{l}\text { posit } \\
\text { Jo sic } \\
\text { on). }\end{array}$ & $\begin{array}{l}\text { mice. } \\
\text { ficant } d\end{array}$ & erence wa & und betwee & mAbs 7 and 153 \\
\hline
\end{tabular}

TBR of MFI for mAb 7 was significantly greater than that for $\mathrm{mAb}$ 153. ROC curve results for $\mathrm{mAb} 7$ demonstrated similarities in accuracy and sensitivity between NIRF imaging and small-animal PET/CT. However, the accuracy for mAb 153 from NIRF imaging was markedly decreased relative to that found from quantitative small-animal PET/ CT. The inconsistent trends observed for mAb 153 may be due to variability in parameters such as incident excitation fluence, tissue absorption, and heterogeneous location of metastatic lesions within tissues and limitations in quantification of NIRF imaging. Because mAbs 153 and 7 possess different epitope binding footprints, the comparison of their imaging performance may not be appropriate relative to the comparison between mAbs 9601 and 153, which do share the same binding epitope on EpCAM. Taken together, these findings nonetheless suggest that high-affinity mAbs are necessary for optimal multimodality detection of metastatic LNs in this PCa model. We expect that the impact of affinity on imaging performance may be more significant using antibody fragments because limited target accessibility due to reduced circulation times may restrict imaging sensitivity.

There are limited reports of quantitative, molecular imaging in animal models of metastatic disease and significant shortcomings associated with studies of antibody-based targeting of human epitopes in mouse models. Because the mAbs used herein possessed low efficiency in targeting homologous mouse EpCAM in vitro, imaging contrast may be artificially high in our studies relative to TBRs that might be expected in human studies. It is also important to note that our quantitative results may have underpredicted specificity because the mAbs tested were whole antibody molecules having Fc regions. Nonspecific binding of full mAbs by Fc receptors on immunocompetent cells is inherent in animal models. The reduction of nonspecific binding can be achieved through modification of the Fc region (35) or by development of dual-labeled specific antibody fragments such as diabodies or singlechain variable fragments to eliminate Fc regions (34). In addition to being a mechanism for nonspecific binding (36), $\mathrm{Fc}$ receptor-mediated interaction with $\mathrm{mAb}$ is known to play an important role in reducing mAb clearance (37), increasing half-life in the blood circulation (38), and therefore increasing background signal that in turn can reduce imaging contrast. These phenomena obviate mAb fragment-based agent development during contrast agent optimization for detection of metastatic LNs in PCa.

Although preclinical NIRF tomography is under development in several laboratories, quantitative optical imaging remains to be validated. Nevertheless, we analyzed in situ NIRF images produced in the present study to evaluate the potential for application of NIRF imaging for intraoperative guidance during LN resection. Fluorescent DsRed reporter gene imaging enabled the rapid identification of LN metastases and provided ground truth for assessing true- and false-positive rates for evaluation of both small-animal PET and NIRF imaging from a single, dual-labeled agent. However, from our imaging studies, it is not obvious whether signals detected were from mAbbound PCa cells within the peripheral, paracortical, or medullary regions or throughout cancer-positive LNs. Although not a focus of the present study, future investigation will include immunohistochemistry to analyze cancer cell location and mAb penetration into positive LNs. Conflicting reports have suggested both penetration and resistance to penetration of blood-borne mAb into the $\mathrm{LN}$ paracortex $(39,40)$. Though the degree of mAb penetration remains to be determined in our model, tumor cells may have impaired access to intranodal compartments in early metastasis, and their detection may not require mAb penetration. At the other extreme, in extensive disease where LN architecture is consumed by tumor, access of the contrast agent to the periphery of metastatic lesions may be sufficient for successful diagnostic imaging. 


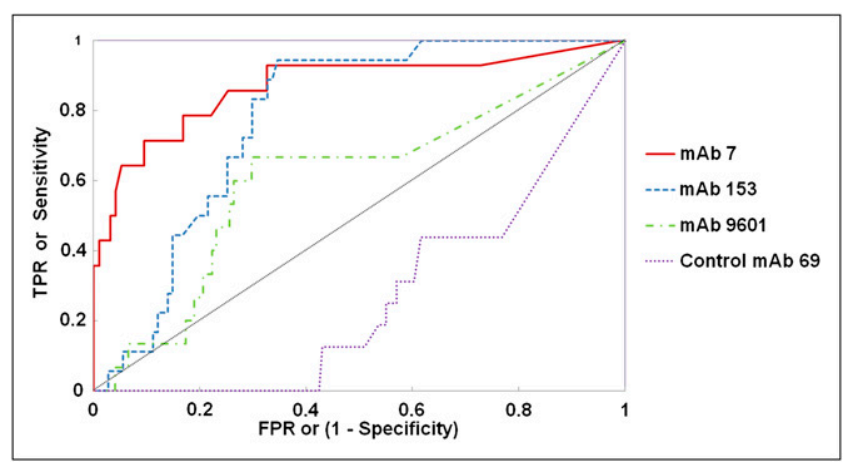

FIGURE 6. ROC curve analyses of TBR of $\% I D / g$ measured from small-animal PET/CT of LNs in mice given dual-labeled mAb 153, 7, 9601, or 69. DsRed fluorescence from reporter gene was considered true-positive indicator of cancer-positive cells in LNs. Truepositive rate or sensitivity was plotted versus false-positive rate (or [1 - specificity]) for each mAb using ascending positive cutoff values, or criteria, that defined positive small-animal PET results. $\mathrm{ROC}$ curve and AUC for each $\mathrm{mAb}$ are demonstrated. Although perfect classification is defined as true-positive rate of 1.0 and false-positive rate of 0 , mAbs 7 and 153 each demonstrated a significantly higher $(P<0.001)$ AUC or concordance rate $(87.0 \%$ and $78.0 \%$, respectively) relative to $50 \%$ random chance line of no discrimination (dotted, diagonal line). No significant differences were found between concordance rates for mAbs 9601 and 69 relative to $50 \%$ nondiscriminatory line. FPR $=$ false-positive rate; TPR $=$ truepositive rate.

The minimum number of cancer cells detectable using either small-animal PET or NIRF imaging was not assessed here, but after the optimization of mAb fragment-based agents it will be studied from the concordance of cytometric analyses of DsRed- and NIRF-positive cells from resected LNs. Although biodistribution studies will also be performed after optimization of a mAb fragment-based agent, it is important to note that the lack of cross-reactivity to mouse EpCAM may result in limited information. Despite the lack of cross-reactivity in the model used, we nonethe- less implemented quantitative small-animal PET/CT to assess the impact of affinity of dual-labeled mAb-based agents for detecting human PCa LN metastasis in an orthotopic mouse model. In addition, we demonstrated the potential for assessing accuracy of NIRF imaging for clinical application, and that development and validation of fully quantitative NIRF imaging is needed for comprehensive analyses of multimodal, NIRF-labeled imaging agents. On the basis of quantitative small-animal PET, our study demonstrates that $\mathrm{mAb}$ affinity affects imaging performance as evaluated using ROC curve analyses.

\section{CONCLUSION}

mAbs for targeting EpCAM on the surface of PCa cells in metastatic LNs in an orthotopic mouse model of human $\mathrm{PCa}$, with binding affinities and biologic activities that surpassed those of commercially available anti-EpCAM, were generated in-house. Using the quantitative analyses of noninvasive small-animal PET/CT images of LNs from our DsRed reporter gene mouse model, we demonstrated a greater concordance between small-animal PET/CT and the DsRed fluorescence indicator for cancer positivity with mAbs 7 and 153 (generated in-house) than with commercial mAb 9601 and significant accuracy rates of both duallabeled in-house mAbs. From analyses of in situ NIRF imaging, we found that dual-labeled mAb 7 was significantly accurate for the detection of metastatic LNs, with sensitivity and specificity rates comparable to or exceeding those found from small-animal PET/CT. Thus, mAbs 7 and 153 are attractive candidates for further multimodal imaging agent development aimed at optimizing sensitivity and specificity for the detection of metastatic LNs in $\mathrm{PCa}$ through affinity maturation to enhance binding affinity and creation of $\mathrm{mAb}$ fragments to reduce circulation times and eliminate $\mathrm{Fc}$ binding regions responsible for nonspecific binding. Quantitative imaging and analyses are essential for contrast agent assessment.

TABLE 3

NIRF Image Analyses Using DsRed-Positive LNs as True-Positive Indicator of LN Metastases

\begin{tabular}{|c|c|c|c|c|c|c|c|c|c|}
\hline \multirow[b]{3}{*}{$\mathrm{mAb}$} & \multirow{3}{*}{$\begin{array}{l}\text { No. of mice } \\
\text { tested }\end{array}$} & \multicolumn{2}{|c|}{ LNs examined in situ } & \multirow{2}{*}{\multicolumn{2}{|c|}{$\begin{array}{c}\text { TBR of } \\
\text { MFI }^{*}\end{array}$}} & \multirow{3}{*}{$\begin{array}{c}\mathrm{AUC}^{\dagger} \\
(\%)\end{array}$} & \multirow{3}{*}{$\begin{array}{c}\text { Sensitivity } \\
(\%)\end{array}$} & \multirow{3}{*}{$\begin{array}{c}\text { Specificity } \\
(\%)\end{array}$} & \multirow{3}{*}{$\begin{array}{l}\text { Optimal TBR } \\
\text { cutoff for MFI }\end{array}$} \\
\hline & & & Percentage DsRed- & & & & & & \\
\hline & & $n$ & positive & Mean & SD & & & & \\
\hline 9601 & 10 & 20 & 45 & 1.48 & 0.4 & $87.0^{\ddagger}$ & 88.9 & 63.6 & 1.09 \\
\hline 153 & 9 & 33 & 48 & $3.45^{\S}$ & 1.8 & 58.0 & 81.3 & 35.3 & 1.97 \\
\hline 7 & 10 & 29 & 38 & $5.24^{\S}$ & 0.8 & $96.0^{\ddagger}$ & 100.0 & 88.9 & 4.06 \\
\hline 69 & 15 & 46 & 26 & 1.58 & 0.1 & 18.9 & 33.3 & 23.5 & $\begin{array}{c}\text { Not } \\
\text { applicable"l }\end{array}$ \\
\hline
\end{tabular}

\footnotetext{
*Mean TBR ( \pm SD) of MFI for DsRed-positive lymph nodes in prostate cancer-positive mice.

${ }^{\dagger} \mathrm{AUC}$ from ROC curve analysis.

${ }^{\ddagger} P<0.001$ and $<0.006$ for mAbs 7 and 9601 , respectively, vs. AUC of $50 \%$ (line of nondiscrimination).

$\S_{P}<0.05$ for mAbs 7 and 153 vs. mAb 69 and mAb 9601 and for mAb 7 vs. mAb 153.

"Not applicable because mAb 69 is isotype control.
} 


\section{DISCLOSURE STATEMENT}

The costs of publication of this article were defrayed in part by the payment of page charges. Therefore, and solely to indicate this fact, this article is hereby marked "advertisement" in accordance with 18 USC section 1734.

\section{ACKNOWLEDGMENTS}

We thank Karen Gore for her technical assistance during this project. This work was supported in part by the National Institutes of Health U54 CA136404, CPRIT Computational Cancer Biology Training Program RP101489, CPRIT Shared Instrumentation grant RP110776, and the Wilson Foundation. No other potential conflict of interest relevant to this article was reported.

\section{REFERENCES}

1. Sevick-Muraca EM. Translation of near-infrared fluorescence imaging technologies: emerging clinical applications. Annu Rev Med. 2012;63:217-231.

2. Shukla-Dave A, Hricak H, Moskowitz C, et al. Detection of prostate cancer with MR spectroscopic imaging: an expanded paradigm incorporating polyamines. Radiology. 2007;245:499-506.

3. Berney DM, Wheeler TM, Grignon DJ, et al. International Society of Urological Pathology (ISUP) Consensus Conference on Handling and Staging of Radical Prostatectomy Specimens. Working group 4: seminal vesicles and lymph nodes. Mod Pathol. 2011;24:39-47.

4. Daskivich TJ, Chamie K, Kwan L, et al. Overtreatment of men with low-risk prostate cancer and significant comorbidity. Cancer. 2011;117:2058-2066.

5. Pilepich MV, Asbell SO, Mulholland GS, Pajak T. Surgical staging in carcinoma of the prostate: the RTOG experience. Radiation Therapy Oncology Group. Prostate. 1984;5:471-476.

6. Musch M, Klevecka V, Roggenbuck U, Kroepfl D. Complications of pelvic lymphadenectomy in 1,380 patients undergoing radical retropubic prostatectomy between 1993 and 2006. J Urol. 2008;179:923-928, discussion 928-929.

7. Cormier JN, Askew RL, Mungovan KS, Xing Y, Ross MI, Armer JM. Lymphedema beyond breast cancer: a systematic review and meta-analysis of cancerrelated secondary lymphedema. Cancer. 2010;116:5138-5149.

8. Spizzo G, Went P, Dirnhofer S, et al. Overexpression of epithelial cell adhesion molecule (Ep-CAM) is an independent prognostic marker for reduced survival of patients with epithelial ovarian cancer. Gynecol Oncol. 2006;103:483-488.

9. Spizzo G, Went P, Dirnhofer S, et al. High Ep-CAM expression is associated with poor prognosis in node-positive breast cancer. Breast Cancer Res Treat. 2004;86:207-213.

10. Went P, Vasei M, Bubendorf L, et al. Frequent high-level expression of the immunotherapeutic target Ep-CAM in colon, stomach, prostate and lung cancers. Br J Cancer. 2006;94:128-135.

11. Fong D, Steurer M, Obrist $\mathrm{P}$, et al. Ep-CAM expression in pancreatic and ampullary carcinomas: frequency and prognostic relevance. J Clin Pathol. 2008;61:31-35.

12. Baeuerle PA, Gires O. EpCAM (CD326) finding its role in cancer. Br J Cancer. 2007;96:417-423.

13. Benko G, Spajic B, Kruslin B, Tomas D. Impact of the EpCAM expression on biochemical recurrence-free survival in clinically localized prostate cancer. Urol Oncol. April 20, 2011 [Epub ahead of print].

14. Mukherjee S, Richardson AM, Rodriguez-Canales J, et al. Identification of EpCAM as a molecular target of prostate cancer stroma. Am J Pathol. 2009;175:2277-2287.

15. Edge SB, Byrd DR, Compton CC, Fritz AG, Greene FL. A. T. AJCC Cancer Staging Manual. 7th ed. New York, NY: Springer; 2010.

16. Zellweger T, Ninck C, Bloch M, et al. Expression patterns of potential therapeutic targets in prostate cancer. Int J Cancer. 2005;113:619-628.

17. Hall MA, Kwon $\mathrm{S}$, Robinson $\mathrm{H}$, et al. Imaging prostate cancer lymph node metastases with a multimodality contrast agent. Prostate. 2012;72:129-146.
18. Münz M, Murr A, Kvesic M, et al. Side-by-side analysis of five clinically tested anti-EpCAM monoclonal antibodies. Cancer Cell Int. 2010;10:44.

19. Prang N, Preithner S, Brischwein K, et al. Cellular and complement-dependent cytotoxicity of Ep-CAM-specific monoclonal antibody MT201 against breast cancer cell lines. Br J Cancer. 2005;92:342-349.

20. Pinkston KL, Gao P, Diaz-Garcia D, et al. The Fsr quorum-sensing system of Enterococcus faecalis modulates surface display of the collagen-binding MSCRAMM Ace through regulation of gelE. J Bacteriol. 2011;193:43174325

21. Canziani GA, Klakamp S, Myszka DG. Kinetic screening of antibodies from crude hybridoma samples using Biacore. Anal Biochem. 2004;325:301-307.

22. Meares CF, McCall MJ, Reardan DT, Goodwin DA, Diamanti CI, McTigue M. Conjugation of antibodies with bifunctional chelating agents: isothiocyanate and bromoacetamide reagents, methods of analysis, and subsequent addition of metal ions. Anal Biochem. 1984;142:68-78.

23. Hall MA, Aldrich MB, Azhdarinia A, et al. Quantifying multimodal contrast agent biological activity using near-infrared flow cytometry. Contrast Media Mol Imaging. 2012;7:338-345.

24. Poczatek RB, Myers RB, Manne U, et al. Ep-Cam levels in prostatic adenocarcinoma and prostatic intraepithelial neoplasia. J Urol. 1999;162:1462-1466.

25. Zhu B, Rasmussen JC, Lu Y, Sevick-Muraca EM. Reduction of excitation light leakage to improve near-infrared fluorescence imaging for tissue surface and deep tissue imaging. Med Phys. 2010;37:5961-5970.

26. Gao P, Pinkston KL, Nallapareddy SR, van Hoof A, Murray BE, Harvey BR. Enterococcus faecalis rnjB is required for pilin gene expression and biofilm formation. J Bacteriol. 2010;192:5489-5498.

27. Holl G, Dorn R, Wengenmair H, Weckermann D, Sciuk J. Validation of sentinel lymph node dissection in prostate cancer: experience in more than 2,000 patients. Eur J Nucl Med Mol Imaging. 2009;36:1377-1382.

28. Janetschek G, Jeschke S, Leeb K, Prammer P, Ziegerhofer J, Sega W. Sentinel lymph node dissection for localized prostate cancer [in Spanish]. Actas Urol Esp. 2007;31:686-692.

29. Giuliano A, Hunt K, Ballman K, et al. Axillary dissection vs no axillary dissection in women with invasive breast cancer and sentinel node metastasis: a randomized clinical trial. JAMA. 2011;305:569-575.

30. Jemal A, Siegel R, Xu J, Ward E. Cancer statistics, 2010. CA Cancer J Clin. 2010;60:277-300.

31. Stoecklein NH, Siegmund A, Scheunemann P, et al. Ep-CAM expression in squamous cell carcinoma of the esophagus: a potential therapeutic target and prognostic marker. BMC Cancer. 2006;6:165.

32. Sears HF, Atkinson B, Mattis J, et al. Phase-I clinical trial of monoclonal antibody in treatment of gastrointestinal tumours. Lancet. 1982;1:762-765.

33. Herlyn M, Steplewski Z, Herlyn D, Koprowski H. Colorectal carcinoma-specific antigen: detection by means of monoclonal antibodies. Proc Natl Acad Sci USA. 1979;76:1438-1442.

34. Olafsen T, Wu AM. Antibody vectors for imaging. Semin Nucl Med. 2010; 40:167-181.

35. Strohl WR. Optimization of Fc-mediated effector functions of monoclonal antibodies. Curr Opin Biotechnol. 2009;20:685-691.

36. Fischman AJ, Rubin RH, White JA, et al. Localization of Fc and Fab fragments of nonspecific polyclonal IgG at focal sites of inflammation. J Nucl Med. 1990; 31:1199-1205.

37. Kosterink JG, McLaughlin PM, Lub-de Hooge MN, et al. Biodistribution studies of epithelial cell adhesion molecule (EpCAM)-directed monoclonal antibodies in the EpCAM-transgenic mouse tumor model. J Immunol. 2007;179: 1362-1368.

38. Datta-Mannan A, Witcher DR, Tang Y, Watkins J, Wroblewski VJ. Monoclonal antibody clearance. Impact of modulating the interaction of IgG with the neonatal Fc receptor. J Biol Chem. 2007;282:1709-1717.

39. Hoffmann-Fezer G, Antica M, Schuh R, Thierfelder S. Distribution of injected anti-Thy-1 monoclonal antibodies in mouse lymphatic organs: evidence for penetration of the cortical blood-thymus barrier, and for intravascular antibodybinding onto lymphocytes. Hybridoma. 1989;8:517-527.

40. Smith GJ, Ingham-Clark C, Crane P, Lear P, Wood RF, Fabre JW. Ex vivo perfusion of intestinal allografts with anti-T cell monoclonal antibody/ricin A chain conjugates for the suppression of graft-versus-host disease. Transplantation. 1992;53:717-722. 